\title{
Organizational Learning: An Assessment of its Impact on Crisis Management in the United Arab Emirates
}

\author{
Mahmoud Kamal Abouraia \\ College of Business, University of Modern Sciences \\ Al-Twar-3, 7A Street, Dubai, United Arab Emirates \\ Tel: +971-4-2646506 E-mail: mkas.abou200@gmail.com
}

Received: November 30, 2017 Accepted: January 4, 2018 Published: January 25, 2018

doi:10.5296/ijld.v8i1.12542ＵRL: https://doi.org/10.5296/ijld.v8i1.12542

\begin{abstract}
The perception associated with organizational learning has been established a long time, however merely in a decade, the notion is extremely acknowledged subject in management studies. The essential part of this research contain the ideas of organizational flexibility structures, assessment of orientation, predisposition to experiment, and enthusiasm to review the environment ideas to understand individual capabilities for knowledge and learning in organization. Empirical evidence publicized that airline industry continues to be the topic of numerous crisis management issues which acquired disastrous effect from the perilousness. Further, it is important to keep in mind that crises can arise as significant factors of change, knowledge, and learning opportunities. The article investigates to evaluate the influence regarding organizational learning toward crisis management in airline industry based on qualitative analysis with airline managers and through supplementary information. The outcomes recommend that airlines should have in-depth and defined techniques for understanding the crises and despite the fact that crisis events and conventional airline accidents remain rare, the requirements for knowledge and learning preparation has vehemently become imperative. It is actually proposing that airlines should apply double-loop learning for its instrumental and policy issues to make sure they will end up more vigilant to signals as well as aggressive while obtaining information for the progress of exigency mechanism.
\end{abstract}

Keywords: Crisis management, organizational learning, airline industry 


\section{Introduction}

In global economic problems, it was recognized that crises have already had a strong impact and even airline industry is not exempted. Until now, it continued to experience unprecedented turbulence, high hedging losses, and risk which undermine the positive and future outlook for airline businesses. The catastrophes take a ubiquitous spectrum of common phenomena and manufactured accidents, including but not limited to snow storm (Mohn, 2015), hurricanes (Granvorka \& Strobl, 2013), earthquake (Brink \& Davidson, 2014), dust storm (Basha et al., 2015; Al-Jumaily \& Ibrahim, 2013), and massive floods (Idris \& Dharmasiri, 2015), while some others are measured events, e.g., hijackings and aircraft bombings (Elias, 2010), passenger scandals (Wang et al., 2014), and terrorist attacks (Sandler, 2014). Despite the weight and duration of such crises, various features showcase to be observed and considered by airline companies in an effort to understand the nature of unpredictable events which includes (i) being highly ambiguous, unexpected or unknown in possible risk, (ii) having a low probability of occurring yet has a high-impact effect which threatens them, (iii) having none or insufficient power athwart the useful information of incidents (Coombs \& Holladay, 2009), and (iv) presenting psychological and institutional challenges for decision making process that leads to refined or undetermined results (Dayton, 2009). One source indicates that these unanticipated events had a substantial impact on passengers and airline companies itself (Manuela Jr., 2011).

In UAE, the occurrences of fatal crashes were unexpected and some travelers might be concerned if the skies or landing site are getting more dangerous because of plane incidents. The Aviation Safety Network, a resource center for comprehensive safety issues of airplane outlined an evidence that six travellers were harmed in a Sudan Airways Boeing 707-330C which descend in the vicinity of Sharjah Flight Terminal on October 21, 2009. Hanif (2016) reported that on September 3, 2010, UPS Boeing 747-44AF was rammed and a couple of passenger passed away around International Airport of Dubai. The latest critical air tragedy on UAE ground occurred on August 3, 2016, after airplane Emirates Flight 521 collided while reaching Dubai International Airport. 300 people on board including crew survived the accident. This tragedy was the first aviation incident of an aircraft managed by Emirates. Normally, the lack of adequate preparation in security and safety systems will highlight the weakness of commercial airlines into the environmental threats or terrorist activity. In this particular, the requisite for crisis management preparation has obtained an alternative emergency in order to mitigate potential negative impacts of unexpected events. It also threatens to tarnish on companies' reputation or engulfed financial losses and may even extensive damage to its stakeholder (Dilenschneider, 2000). Considering the susceptibility of the airline businesses to unexpected emergency and the significant role of organizational learning, this article strives to discuss the issue of organizational learning and knowledge management in airline's crisis management.

\section{Literature Review}

\subsection{Airline's Crisis Management Response}

As crises occur all the time, sufficient planning and preparation in advance will enable 
airlines to cope with crises in a volatile situation. In an ideal world, airline manager is expected to perform their duties professionally and compassionately. The notion for airline crisis management have received continuous attention in the public while nearly all airline companies have crisis management to minimize negative effect of critical crises to stakeholders (McDonald et al., 2010), legitimacy (Stephens et al., 2005; Hale et al., 2005) and firm's reputation (Sohn \& Lariscy, 2014). A crucial issue in assessing crisis recovery is how individuals react and respond optimally to airline accidents. Since the unprecedented scale of the incident draws international outrage, individuals use the concept of "sense-making" in recognizing the unpredicted, novel, or complex circumstances (Maitlis \& Christianson, 2014). Choo (2001) stated that the buzzword "sensemaking" is dictated by formal, methodical checking (is often both belief-driven and action-driven) that is designed toward analyzing the sensible information of which is taking place in the physical workplace. Therefore, an understanding of these factors is vital for protecting the organization's reputation and future interaction with individuals.

In heuristic perspective, Siomkos' (2000) cognitive pattern is impeccable for figuring out individual reactions wherein a disaster unfolds. Just to illustrate, a frequent traveler seems sensible of air travel emergencies as outlined by their unique personal airborne encounters like service quality, travelers' socioeconomic characteristics, and the purpose of the trip. Further, they make an attempt to be a dynamic part of the expedition rather than just a passenger traveling to one place or destination. Often brochures are certain to travel and leisure activities in which they may be zero option to travel. They cognitively manage the need for traveling by not taking any notice of safety uncertainties they may have. Disaster sense-making is likewise contingent upon the consumer faith in safety capability of airline carriers as well as government safety commercial infrastructure. The awareness into a certain airline's safety provides a significant role in the understanding of accidents and their implications. Research indicates that safety is the most important feature that cannot be compromised (Chen et al., 2008). A good safety track record allows vacationers better self-esteem in the airline's capability to avert complications that may turn into tragedies.

Experts believed that the avenue to customer satisfaction drives directly through employee behavior which is a function of employee morale. In a malevolent-type crisis, it's important that organization should implement the identification theory to rebuild employee morale and increase employees' affective commitment (Stinglhamber et al., 2015). In addition, they put more stringent processes or supervision, employee training or even a comprehensive internal and external audit to ensure quality and service standards are upheld (Chan, 2015). A profound and excessive outcome of strong organizational identification is undoubtedly an improved level of organizational commitment among airline employees. This notion is paralleled with the research by Pangarkar (2016) that organization with a strong commitment to doing the right thing for employees and a high readiness are most likely to effectively respond to crises and contribute to organizational mission and goals. In the organizational context, the most important goals are to recover the business, elevate the practicality of plan development effort and tailored to the organizational strategy and goals. This sort of strategies consists of business impact analysis, emergency management planning, 
implementing notification and monitoring systems, usage of media relation campaigns, and stakeholders, customers and employees knowledge and communications (Ki \& Brown, 2013; Taneja et al., 2014).

As mentioned previously, the incidents on 3 August 2016 of Emirates Airline Flight 521 have experienced a destructive effect on the families and airlines. According to the report, it becomes the most expensive accident to the economy of UAE (Clarke \& Butalla, 2016). Airline businesses utilized communication technologies such as social media to collect, process, and disseminate information during difficult economic conditions as employees experienced constant internet access at work. Nonetheless, there are unquestionable commonalities that are able to adversely affect an organization, and they are required to be looked at business and management stages with a purpose to discover efficient methods for the transforming surroundings. These crises include financial expectations, corporate lawsuits, or even company's credibility, etc (Varnai, 2005). In spite of this, the usual organizational reactions to predicament are organizational downsizing and employment termination. Countless research has emphasized the adverse outcomes of the so-called "trimming the fat" with the employee-organization interrelations. The unfavorable implication of downsizing on employees includes diminishing loyalty, decreasing commitments of the employees and the perceptions of the employees about their jobs (Rehman \& Naeem, 2012). After eliminating staff positions, existing human resources might, as an example, have to deal with the substantial pressure, contrition as well as skepticism in the stewardship of an organization (Petzall et al., 2000). Hence, mediocre recognition with the management executives might pertain to the decrease functionality of staff members (Van Dick et al., 2016).

Because of the valuable participation in interpersonal assets, employment terminations include adverse effects on the subsequent organizational performance. Most organizations have been shown that layoffs lead to stagnation or deterioration of organizational profitability, product development, and service quality. Additionally, it seasoned a contingency of "dirty dozen" as an effect of eliminating positions (Cameron, 2012). The dirty dozen contains the twelve most common human factors that cause or contribute to an accident or injuries from occurring. These types are; distraction, stress, pressure, complacency, fatigue, lack of communication, lack of assertiveness and norms, lack of resources, lack of knowledge, lack of teamwork, and lack of awareness (Begur \& Babu, 2016). These adverse performance effects of layoffs could lead to not only less profit for the organization but exploitation of social interactions, resistance to change, and lessened information sharing. Aside from that it is outlined by the principles of unique job procedures, which are convinced that work protection is necessary for undertaking continual advancement as well as effectiveness that value human resources and management. When layoffs are being used as a principal dealing with the reaction to crisis, the consequential deprivation of employment terminations alleviates the particular strength and rehabilitation turning out to be required (Gittell et al., 2006). Further, management must be prepared to address their effects and communicate effectively to all employees, explaining why the downsizing is necessary and how terminated employees were selected. 


\subsection{Organizational Learning in the Landscape of Crisis Management}

An identifiable event such as catastrophe routinely exposes enormous difficulties for an enterprise that can potentially impair its own existence. Nonetheless, the research argues that companies are able to grasp these complexities to gain knowledge from predicaments. This strategic intervention of learning concept has been increasingly adopted by organizations for gaining competitive advantage and stabilizing organizational success. Kantamara and Ractham (2014) stated that once a miscalculation is recognized or perhaps an issue is observed, top executives usually generate an organizational assessment in accordance with the collection of policies, techniques, procedures, and expectations without considering these individuals. This viewpoint is considered as one of the most understandable definitions of organizational learning (OL) by Argyris and Schön in 1978. Gomes and Wojahn (2017) stated that $\mathrm{OL}$ enables to establish, ascribe and encompass understanding and knowledge. It will likewise develop organizational effectiveness and functionality by boosting the utilization of the limitless expertise of their employee members. To craft an effective response, especially in the time of sensitive crises organizations should first strategize the appropriate response strategy and acceptance of responsibility, afterward coalesce with the suitable approach technique to emergency classification (Coombs and Holladay, 2008). Airline managers should ensure that the content of the response is consistent, comprehensive and accurate. Lastly, convey the message to the right spokesperson (Grundy \& Moxon, 2013), according to the needs of the target audience and multiple forms of communications should be considered.

Paulin and Sunesson (2012) stated that in the process of OL, awareness is developed cooperatively, and that distinction can be transferred to individuals and shared within the systems, different groups as well as organizations. Within this measure, OL is described as the quantity of personal understanding. It will be the organizational reference that enables the business entity to cultivate routines of advancement as well as inventiveness, analyze potentials including limits, interpret past success and failure, and recognize the objective of reflection considering an essential requirement in the organizational practice and theories (Hilden \& Tikkamaki, 2013). Productive OL leads to maintain long-term firm performance, development of positive learning attitudes and a self-renewal climate, and enhancement in organizational capability. Scholars and practitioners pointed that there are a couple of significant innovations in OL, with the change from preparation of program to educational learning, that have precipitated in the improvement of the understanding the enterprise, among them involving training to management policy, the emerging role of chief learning officer in organizations, examining ethical behavior by HRD practitioners as a means of making decisions, capturing intellectual capital (Gilley et al., 2009), as well as implementation of empowerment to operations (Vasenska, 2013). From the management viewpoint, crises often open a new avenue of opportunity for reform for better or worse. Topping (2002) detailed that once an enterprise is at a crossroad of unexpected emergency, it entails indispensable and impressive corporate governance to distinguish, segregate as well as administer the downturn.

Griffin (2014) explained that experiencing uncertainty is the approach to accurate a business enterprise seeing that the occasion might exhibit a pivotal matter for sizeable modification to 
an evidently uncontrollable number of unique situation. It can also replace the direction of specialists to anticipate and even argue with their leadership styles, values, and principles including insights with the societal and natural environment, likewise the competence of well-designed management set-ups, procedures, policies, technology, or culture. Further, crisis experience is accompanied with depression, social isolation, a perception of deterioration, intense reactions of rigidity, trauma, posttraumatic stress disorder which may lead to conflict and destructive to change (Dekker, 2013) or trigger to change (Palmer, 2012), for instance, resulting in more rigorous thinking and critical reflection. Seeing that, a useful crisis management procedure turns out to be more necessary for the extensive strategic advantage of the organizations. This process involves constantly learning from and assessing the present situation, understanding the prospective outlook, as well as contemplating ideas to complete the preferred results by means of the execution of powerful preparations (Hough and Spillan, 2005).

\section{Research Methodology}

The qualitative analysis prototype has recommended as the practical tools and procedures for documents selection and investigation in business, organization studies, and management (Lawrence and Tar, 2013). Whereas concentrating on interpretation in the perspective, it entails an evidence compilation instrument being susceptible to concealed interpretation whenever acquiring and even explaining details. Academic scholar emphasizes that despite the fact that this measurement accepts a certain amount of attributes in commonplace, this is ascertained based on its own constitutional disciplinary procedure, in which its groundwork could attract from, the way an evaluation is perhaps developed, and which the purpose of the investigation could be, as well. Also, the essence of qualitative analysis would be to seem sensible of and even acknowledge practices among descriptions in an effort to flourish a noteworthy display without negotiating their own elegance and measurement of a given direction (Leung, 2015). Pertaining to this review, it was clear that qualitative analysis considered an effective strategy to scrutinize OL in the framework of tourism crisis management.

\subsection{Sampling and Participants}

This exploration is located within the tourism sector of UAE. The qualitative analysis technique was utilized to lead this research project. The survey model has identified and determined by the chain-referral research strategies. We adopt chain-referral cross section from individual telephone or emails to assist recognize potential research respondents in studies where respondents have the ability to bestow the quality degree of evidence (Robinson, 2014). Atkinson and Flint (2001) stated that snowball or chain-referral sampling is a method that has been used frequently to conduct a qualitative sociological research. According to this method, selected participants are hence accustomed to recommend research specialists towards additional individuals or recruit future subjects from among their acquaintances who had a number of capabilities which can be of scientific studies curiosity. As cited by Patten (2016), the representation dimension with this survey considered by utilizing the measure of "saturation". At the purpose of which a few respondents are not able 
to interact with unique facts and information that contributes to the distinguishable of extra designs, the academic scholars could presume that the detail selection approach could have been imbued thoroughly. At that point, no additional respondents are studied because new types of information are unexpected to be attained by building the model scale. Consequently, the saturation awareness could figure out the last pattern of specifications.

The whole of twenty-one strategic marketplace shareholders in diverse tourism commerce from the United Arab Emirates (Ajman, Dubai, Abu Dhabi, Ras Al-Khaimah, Fujairah, Umm Al-Quwain, \& Sharjah) were engaged in this research (Table 1). They were from five tourism industries: aviation companies, legitimate hotels and motels, travel representatives and tour proprietors, tourist destinations, and the tourism government bodies in UAE. The largest number of surveyed applicants possessed excellent rankings in their commercial establishments, such as president, director, chairman, albeit certain were general managers. The scale of airline communities was multifaceted, varies from small size travel and tourist agencies to average and significant size businesses, which include opulent overseas hotels as well as air travel companies. Most of these companies were financially-focused, although couple of them was being non-business entities. Paraskevas et al. (2013) mentioned that these business communities involve of countless cultural groups that showcased their organizational intricacies as well as work-related demarcation. The managerial qualities of them might be described with different arrangements of three significant decision-making designs for instance authoritarian, collaborative, and laissez-faire managerial qualities (Jung et al., 2014). As a preliminary stage to ascertain the leading respondent, the researchers directly described the Travel and Leisure Agencies Council that has been the head office as well as the primary reliable bureaucracy for tourism in Abu Dhabi. During this period, were Johnson (2005) used "zero stage sample", the researchers surveyed and questioned the individual who are accountable for tourism crisis management as well as requested their coordination to determine the following commendable societies. We were earmarked for the prospective individuals from various marketplaces, for instance hotel and motel association, tour and travel operator association, the state tourism authorities, and alliance of tourist attractions and air travel companies. The right individuals whom we were explained often the top-notch professionals of their business entities, albeit there have been a couple of respondents who were not in the highest positions yet somehow acquired dedication for the crisis management. Respondents got no less than 5-25 years of encounters in various sectors in the travel and tourism businesses. Of 21 respondents, 16 were males and the remaining 5 were females. 


\section{Al Macrothink}

International Journal of Learning and Development

ISSN 2164-4063 2018, Vol. 8, No. 1

Table 1. Research Respondents

\begin{tabular}{|c|c|c|c|c|c|}
\hline Rank & Organization & Number & Venue & Position & Gender \\
\hline 1 & $\begin{array}{l}\text { Travel and Tourism Agencies } \\
\text { Council }\end{array}$ & 1 & Abu Dhabi & Secretary General & M \\
\hline 2 & Etihad Airways & 1 & Abu Dhabi & $\begin{array}{l}\text { Sales \& Marketing } \\
\text { Manager }\end{array}$ & M \\
\hline 3 & Hilton Hotels and Resorts & 1 & Abu Dhabi & Sales Manager & $\mathrm{F}$ \\
\hline 4 & $\begin{array}{l}\text { Ajman Tourism Development } \\
\text { Department }\end{array}$ & 1 & Ajman & Director & $\mathrm{M}$ \\
\hline 5 & Fly Ajman Travel Agency & 1 & Ajman & General Manager & M \\
\hline 6 & Ramada Beach Hotel & 1 & Ajman & Operations Manager & M \\
\hline 7 & $\begin{array}{l}\text { Department of Tourism and } \\
\text { Commerce Marketing }\end{array}$ & 1 & Dubai & General Manager & M \\
\hline 8 & $\begin{array}{l}\text { International Association of Hotel } \\
\text { General Managers }\end{array}$ & 1 & Dubai & Operations Manager & M \\
\hline 9 & Regal Tours Worldwide & 1 & Dubai & President & M \\
\hline 10 & $\begin{array}{l}\text { Fujairah Tourism and Antiquities } \\
\text { Authority }\end{array}$ & 1 & Fujairah & Chairman & M \\
\hline 11 & Miramar Al Aqah Beach Resort & 1 & Fujairah & Relations Manager & $\mathrm{F}$ \\
\hline 12 & East Coast Tourism & 1 & Fujairah & Manager & M \\
\hline 13 & $\begin{array}{l}\text { Ras Al Khaimah } \\
\text { Development Authority }\end{array}$ & 1 & Ras Al Khaimah & $\begin{array}{l}\text { Director of Business } \\
\text { Development }\end{array}$ & $\mathrm{F}$ \\
\hline 14 & Rixos Bab Al Bahr & 1 & Ras Al Khaimah & Director of Finance & M \\
\hline 15 & Al Safina Travel and Tourism & 1 & Ras Al Khaimah & Branch Manager & M \\
\hline 16 & $\begin{array}{l}\text { Sharjah Commerce and Tourism } \\
\text { Development Authority }\end{array}$ & 1 & Sharjah & $\begin{array}{l}\text { Director of Marketing } \\
\text { and Communications }\end{array}$ & $\mathrm{F}$ \\
\hline 17 & $\begin{array}{l}\text { Sheraton Sharjah Beach Hotel \& } \\
\text { Spa }\end{array}$ & 1 & Sharjah & $\begin{array}{l}\text { Director of Revenue } \\
\text { Management }\end{array}$ & $\mathrm{F}$ \\
\hline 18 & $\begin{array}{l}\text { Sharjah National Travel and Tourist } \\
\text { Agency }\end{array}$ & 1 & Sharjah & Managing Director & M \\
\hline 19 & Sapna Travel and Tourism & 1 & $\begin{array}{l}\text { Umm } \\
\text { Quwain }\end{array}$ & Office Administrator & M \\
\hline 20 & Dreamland Aqua Park & 1 & $\begin{array}{l}\text { Umm } \\
\text { Quwain }\end{array}$ & Sales Manager & M \\
\hline 21 & $\begin{array}{l}\text { Umm Al Quwain National Travel } \\
\text { Agency }\end{array}$ & 1 & $\begin{array}{l}\text { Umm } \\
\text { Quwain }\end{array}$ & Executive Secretary & M \\
\hline
\end{tabular}

\subsection{Data Collection}

The detail selection practice opted within the research is through a semi-standardized interview in accordance with the prepared questionnaires in the United Arab Emirates (Ajman, Dubai, Abu Dhabi, Ras Al-Khaimah, Fujairah, Umm Al-Quwain, \& Sharjah). These destinations remain the global marketplace for both intra-regional and international travellers while having witnessed diverse economic adversities to the tourism sector (Mansfeld \& Winckler, 2015; Schiliro, 2013; Habibi, 2009). The commercial competitors in the similar 
destinations observed no less than one or a couple of unexpected emergency in their enterprises and obtained an excellent understanding in tourism crisis management. Likewise, since this survey applied a chain-referral technique, respondents were unveiled being the excellent and competent individuals in managing the event by using confidential connections. Individual meetings took from around 30-60 minutes with the use of speech and sound recorder, despite that physical transcripts were created from 4 dialogues at the demand of the applicants. A unique array of relevant inquiries was asked seeing crisis management and reactions of enterprises in before, during and after a catastrophe as well as repercussions of emergencies in the tourism sector. Moreover, awareness of tourism societies, organizational knowledge and learning, and incorporate a new changes as well as barriers to effective learning.

\subsection{Data Analysis}

Most of the consultation was deciphered precisely for exploration, so the manuscripts were transmitted to the research respondents for the legitimacy of subject material and viability of understanding. Whatever ratification prepared in the survey items were captured being the principal information for the investigation, whereas the data initially inscribed was eliminated. This procedure, often referred to as "member checking," continues each psychological as well as physical authenticity to the research findings (Thomas, 2017). The thematic qualitative measurement as well as tabulating approaches was equipped to analyze, examine, and record the patterns (themes) across qualitative information and to systematically gain knowledge during an interaction. This is reliable scheme that upholds a clear-cut and upfront linkage among decisions and the written material of leading scientific studies. Themes were extracted from interview transcripts. The conceptual framework of the thematic analysis for the dialogues was structured resulting to the analytical placements by Braun and Clarke (2012). As emphasized by this process, interpreted research items are figure out by the academic scholars to familiarize the scientific documents, produce preliminary instructions, as well as locate designs among information. At the different phase, structure checking is created to monitor if the established designs were being employed in contrast to the coded mechanisms as well as the comprehensive information prepared and developing a sectional diagram of the examination. Exemplifying and identifying designs is an additional phase to detox the disputes of them and the universal description of the examination clarifies, establishing lucid rationales and brands per content. In the last phase, the outcomes were distributed with respect to the groundwork topics, investigation requirements, and the literature review. The objective within this phase ought to inscribe the confined research to impart the well-designed statement of the detail in a better way that persuades the audience of the benefits of the experiments and its genuineness (Guest \& MacQueen, 2012).

\section{Research Findings}

The airline industry has recognized that OL can present a unique opportunity to organizational resilience in coping with crises despite the stressful changes to the situations. The concept of learning can be applied before, during, and after an extreme situation, whether the organization applies the lesson learned toward next crises, or learns from the external 
uncertainties created by crisis situations (Simmons, 2009), or even treats the learning as emergent phenomenon whose history is an essential component of understanding (Gilpin \& Murphy, 2008). Using this approach enables airlines to generate new knowledge in areas significant for their organizational goals. Moreover, airlines that are able to stimulate learning can handle and develop creative solutions to more complex challenges. For this reason, it is necessary for airline companies to adapt OL and a clear communication strategy, so as not to continue the detrimental influence on multinational's trustworthiness and authenticity as well as to stakeholders. Literature indicates that countless the predicaments, the boundless the assistance of airlines for knowledge and learning as it guarantees better even more efficacious reactions to a complicated as well as impressive atmosphere (Allen et al., 2002).

The findings revealed that organizational learning influences through different factors. Innumerable extensive disputes in understanding businesses are context, history, and survival. The perception of context is innately associated with nonchalantly designed variables. Marling (2012) presented learning as a social and cultural process that occurs in the context of human relationships and activity. In this social formulation of learning, the sociocultural context is not merely the location of learning. The sociocultural context impacts on how individual understand (by means of involvement in historical events) then what could be understood (societal practices), which is themselves a component of what exactly is learnt. An ultimate facet of OL to envision could be airlines ought not to fall short on its informative competencies before employees are planning to leave. Further, they should traverse proficiently among extremities that airline vendors consider being distinctive. For instance, Singapore Airlines lodges an intense weight on each feature of choice, training courses, as well as accountability particularly for their own spokesperson (Wirtz et al., 2008). The concept could be excellent OL are unable to act upon the newest employees, along with potential employees caused by the exposures, social interests, coupled with standards having built up in the process. The success and survival of airlines depend on the organizational culture that considers advancement and originality. These demands are imperative to an airline that enjoys discovering and generating innovative designs or even developing a platform wherein advancement and originality are regarded to be the principal of historical standards amongst complex technology and other improvements (Martins and Terblanche, 2003).

The second factor identified in this research is the situation of history. The repercussions of the history incidents as well as challenges in understanding the concept of learning could influence a future outlook of entire OL process in that airline. Dierkes et al. (2003) mentioned that a linked aspect of the learning process is the assessment of the airline company as an archetype of past learning and even the creation of new and the actualization of learning in action (Angelo, 2013). The hypothesis of multi-store memory being the repository of both individual and organizational awareness is expounded by explanation to the keywords of "mental models" that enable the achievement along with the airline company of cutting-edge experience. The aptitude of an airline company to circulate and even integrate each modern and obsolete detail shall reveal on the permanency of building an OL using vigorous norms. Finally, survival differences are the necessary principle to achieve OL within the airlines. It is 
the mechanism that a person may use in order to sustain life in any type of natural or man-made environment. In critical literature, OL academicians showcase that survival is an imperative entity in learning. Therefore, in order for airline businesses to manage learning consistently and exist long-term systematically, concentration should be connected on various critical features: human beings, strategies, as well as technological innovation for the purpose leveraging knowledge (Omotayo, 2015). Martensson (2000) considers knowledge and involvement of management being a paramount requirement for an organization in continuing and upholding viable interest. The Lufthansa Airlines offers an example of a company that has a clearly defined task for its survival and operation, namely assigning top managers to define and understand the threat, invests time in research, and estimates the risks in worse-case scenario (Bruch \& Vogel, 2011).

It is interesting to note from the findings that historic documents on airline flight security measure implies that countless airline businesses becomes inexistent at some level attributable to misinterpretation designed by their managerial system. However, protecting against perhaps detrimental discrepancies is certainly not engaged with intense. In certain cases, if the damages of glitches are accurate as well as rich in the context of missed life or even wellness, broad worker management levels and safety management systems can be exploited separately to forecast calamity ratios (Wachter \& Yorio, 2014). It may also represent the necessary first step in reducing the risk of errors. According to the Aviation Safety Network, the quantity of victims attributable to airplane flight continues to fall dramatically, by any measure. Totally from the thirty million commercial and business flights in 2014, there have been just twenty-one painful during collisions, which signify the individual possessed a 0.000007 probability of appearing available to that aircraft, or approximately 1 in 0.00143 billion (Steele, 2015). Researchers consider air travel to be a system consisting of four elements: software, hardware, environment, and liveware. To maintain aviation safety is to keep the system intact and functioning (Fink, 2010). Certainly no operation is quite secluded from the rest; when a single component is inadequate, it has unfavorable influences on other individuals.

In the framework of the edification process, the findings argue that learning occurs in different instances. Initially, business establishments obtain the features outlined; it signifies their blueprint corresponds to the natural situations. Secondly, acquisition of skills or knowledge transpires during an inequality among desired goals and end results; in case it will be correct, this implies the disparity switched into uniformity. It likewise publicizes that entities never implement the initiatives that construct the knowledge. Nonetheless, this can be the personalities' deportment to the companies that resulted in the acquisition of skills. Argrys and Schon (1996) raised two levels of learning influenced by their hypothesis of mechanism (the single-loop learning and the double-loop learning) as shown in drawing 1 . The single-loop learning consists of one feedback loop when individuals or organizations amend their activities according to the diversity between expected and reached effects. This valuable knowledge, which indeed carries temporary repercussions, may result in repetitive and routine results (Liggett-Nichols, 2013), while the root causes are stay behind. By using single-loop learning, it will turn out in a minimal solutions and adjustments. With the 


\section{Macrothink}

double-loop learning, it may change the primary factors of the complicated engagement in order to deepening the awareness of individual expectations as well as the robust decision-making in everyday processes. The values, repercussions, and policies are crafted which enable to generate a unique objectives and preferences (Pierre et al., 2011). For instance, airline directors can re-assess the all-inclusive revenues and marketing operations to ensure it will have zero percent of those imbalances later on.

The main aim in this context is enabling airlines to practice double-loop learning as compared to single-loop learning at all levels with a view to establish a constant or inferred improvement in individual's perspective. By doing this, airlines have the ability to eradicate the core reasons for the problem that renders to acknowledge or act in an explicit, inadequate or uneconomical direction. Nevertheless, the knowledge capability of airlines is determined by accepting the lessons absorbed from operational procedures and apparently their organizational culture. Consequently, instructive philosophy as well as double-loop learning might provide insights into the causes of changes. With more insight airlines and stakeholders are better to accept it (Blanke, 2016), as well as pointing to possibilities to take advantage of new opportunities. When airlines have a continuous planning for understanding available options regarding crisis management system, it doubtless generates to condensed OL.

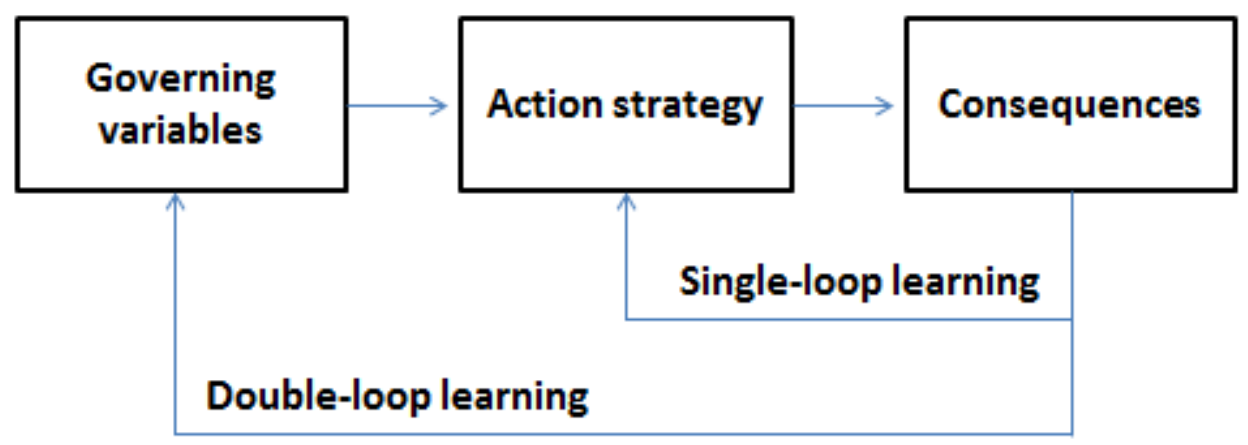

Figure 1. Organizational Learning Theory (Argrys \& Schon, 1996)

\section{Discussion}

In spite of the optimistic position of the OL in the airline crisis management, surprisingly less serious outcomes manifested in the effective crisis management plan and organizational contingencies. Airlines seemed to be the most active sectors which acknowledged and experienced the application of organizational learning in their crisis management framework. This could be due to the fact that airline industry have had well-documented management structure and more accumulated knowledge flowing from concrete experiences (Lalonde, 2007). Moreover, this is because high reliability airline businesses nearly always achieve "error-free operations" all the time (Rains, 2014) and or else, they are qualified to understand crises. When airlines applied double-loop learning can obtain considerably a narrow destructive impacts of crises, and consequently it took relatively short time to overcome from uncertainties rather than those who intended to practice single-loop learning. This outcome is coherent with the academic work of Richardson (2014) that practicing double-loop learning 
supports aviation industry to limit decision latency or its negative impact through profound iterative learning, and hence firm improvement.

Those stakeholders and relevant public sector agencies which utilized double-loop learning in the crisis management affirmed that post-mortem, healing, and development of the new state have improved them to outline and exercise a robust strategy to wrestle the negative impacts of the learning process. This viewpoint expressed within the research of Faulkner and Vikulov (2001), which argued a prompt and effective response to any emergency incidents are more expected if individuals and aviation team participated in every phase of strategic process and evaluating alternative responses to the different event scenario in advance. A post-mortem review has helped them to ascertain their imperfections, question their past assessments and organizational rules, principles, and expectations and employ an innovative changes (Zhang et al., 2015).

\section{Conclusion}

Generally, OL is referred to as taking place in different difficulties. Initially, it arises the moment a business enterprise exceeded the objectives it had been attempting to actualize. Subsequently, it includes an equivalent among the featured movements as well as the outgrowth. Secondly, learning and knowledge shows up once the researchers categorize the incongruity concerning the purposes and consequences and rectify it.

It is imperative to realize that companies never undertake the measures that deliver learning. As an alternative, it serves the human beings who embody as representatives of establishments and provide the characteristics that triggers towards learning. Even so, institutions are capable of doing elements which often impact on what human beings structure as the issue, develop as an alternative and etc. Of course, entities can even carry predispositions and pressures to the knowledge and learning systems. An illustration of the restriction is the narrow accessibility of individual's awareness for figurative data preparation.

As a final point, single-loop as well as double-loop learning can be used by every airline businesses. It is indeed that aviation firms ought to degrade double-loop irregularities into single-loop circumstances as single-loop disputes are further convenient to manipulate. It may be given that single-loop learning is suitable for the standard procedure, monotonous glitches which assist us to undertake our day-to-day operations, whereas double-loop learning works great in sophisticated situations.

\section{References}

Angelo, A. L. (2013). Applied embodiment towards optimization within the organizational ecosystem: The evolution of best practices through the design and implementation of learning laboratory experience modules (Unpublished master's thesis). University of Pennsylvania.

Allen, W., Kilvington, M., \& Horn, C. (2002). Using Participatory and Learning-Based Approaches for Environmental Management to Help Achieve Constructive Behaviour Change (pp. 1-51, Rep.). (2002). Lincoln, New Zealand: Landcare Research. 
Al-Jumaily, K. S., \& Ibrahim, M. K. (2013). Analysis of synoptic situation for dust storms in Iraq. International Journal of Energy and environment, 4(5), 851-858.

Argyris, C. S., \& Scho, D. (1996). Organizational learning II: Theory, method and practice. Massachusetts: Addison-Wesley.

Atkinson, R., \& Flint, J. (2001). Accessing Hidden and Hard to Research Populations: Snowball Research Strategies. Social Research Update. University of Surrey: UK.

Basha, G., Phanikumar, D. V., Kumar, N., Ouarda, T. B. M. J., \& Marpu, P. R. (2015). Investigation of aerosol optical, physical, and radiative characteristics of a severe dust storm observed over UAE. Remote Sensing of Environment, 169, 404-417. https://doi.org/10.1016/j.rse.2015.08.033

Begur, S. H., \& Babu, J. A. (2016). Human Factors in Aircraft Maintenance. International Advanced Research Journal in Science, Engineering and Technology, 3(3), 14-17. DOI 10.17148/IARJSET.2016.3303

Blanke, M. (2016). Learning from evaluations of crisis-exercises (Unpublished master's thesis). University of Twente.

Braun, V., \& Clarke, V. (2012) Thematic analysis. In H. Cooper, P. M. Camic, D. L. Long, A. T. Panter, D. Rindskopf, \& K. J. Sher (Eds), APA handbook of research methods in psychology, Vol. 2: Research designs: Quantitative, qualitative, neuropsychological, and biological (pp. 57-71). Washington, DC: American Psychological Association.

Brink, S., \& Davidson, R. (2014). Framework for comprehensive assessment of a city's natural disaster risk, Earthquake Spectra, preprint available online.

Bruch, H., \& Vogel, B. (2011). Fully Charged: How Great Leaders Boost Their Organization's Energy and Ignite High Performance (Illustrated ed.). Boston, Massachusetts: Harvard Business Press.

Cameron, K. (2012). Effects of virtuous leadership of organizational performance. In S. I. Donaldson, M. Csikszentmihlyi., \& J. Nakamura (Eds.), Applied positive psychology: Improving everyday life, health, schools, work and Society (pp. 171-183). East Sussex: Rout ledge

Chan, C. (2015). How to rebuild trust post-crisis. Newsroom, Bell Pottinger, Hongkong. Retrieved from http://www.bellpottinger.com.

Chen, A. H., Peng, N., \& Hackley, C. (2008). Evaluating Service Marketing in Airline Industry and Its Influence on Student Passengers' Purchasing Behavior Using Taipei-London Route as an Example. Journal of Travel and Tourism Marketing, 25(2), 149-160.

Choo, C. W. (2001). Environmental scanning as information seeking and organizational learning. Information Research, 7(1). Retrieved from http://informationr.net/ir/7-1/paper112.html.

Clarke, K., \& Butalla, N. (2016). Emirates incident: Guess what costs \$1 million a minute? 
Khaleej Times. Retrieved 4 August 2016.

Coombs, W., \& Holladay, S. (2008). Comparing apology to equivalent crisis response strategies: clarifying apology's role and value in crisis communication. Public Relations Review, 34(2), 252-257.

Coombs, W. T., \& Holladay, S. J. (2009) .Further explorations of post-crisis communication: Effects of media and response strategies on perceptions and intentions. Public Relations Review, 35(1): 1-6.

Dayton, B. W. (2009). Crisis Management: A Definition. International Cyclopedia of Peace. Oxford University of Press, 1-13.

Dekker, S. (2013). Second Victim: Error, Guilt, Trauma, and Resilience. Boca Raton, FL: CRC Press

Dierkes, M., Antal, A. B., Child, J., \& Nonaka, I. (2003). Handbook of Organizational Learning and Knowledge. New York: Oxford University Press,702.

Dilenschneider, R. L. (2000). The corporate communications bible: Everything you need to know to become a public relations expert. Beverly Hills: New Millennium, 120-142.

Elias, B. (2010). Screening and Securing Air Cargo: Background and Issues for Congress. Congressional Research Service, 1-18.

Faulkner, B., \& Vikulov, S. (2001). Katherine, washed out one day, back on track the next: A post-mortem of a tourism disaster. Tourism Management, 22(4), 331- 344. doi:10.1016/S0261-5177(00)00069-8

Fink, G. (2010). Stress of War, Conflict and Disaster. Burlington, MA: Elsevier Science.

Gilley, J. W., Dean, P. \& Bierema, L. (2009). Philosophy and Practice Of Organizational Learning, Performance And Change. Hachette UK.

Gilpin, D. R., \& Murphy, P. J. (2008). Crisis management in a complex world. New York: Oxford University Press.

Gittell, J. H., Cameron, K., Lim, S., \& Rivas, V. (2006). Relationships, Layoffs, and Organizational Resilience: Airline Industry Responses to September 11. Journal of Applied Behavioral Science, 42(3), 300-329. http://dx.doi.org/10.1177/0021886306286466

Gomes, G., \& Wojahn, R.M. (2017). Organizational learning capability, innovation and performance: study in small and medium-sized enterprises (SMES). Revista de Administração (2017), http://dx.doi.org/10.1016/j.rausp.2016.12.003

Granvorka, C., \& Strobl, E. (2013). The impact of hurricane strikes on tourist arrivals in the Caribbean. Tourism Economics, 19(6), 1401-1409.

Griffin, A. (2014, April 23). What does it mean to be a crisis ready organization? Retrieved April 6, 2017, from http://www.continuitycentral.com/feature1172.html 


\section{Macrothink}

International Journal of Learning and Development

ISSN 2164-4063 2018, Vol. 8, No. 1

Grundy, M., \& Moxon, R. (2013). The effectiveness of airline crisis management on brand protection: A case study of british airways. Journal of Air Transport Management, 28, 55-61. http://dx.doi.org/10.1016/j.jairtraman.2012.12.011

Guest, G., \& MacQueen, N. (2012). Introduction to Thematic Analysis. Applied Thematic Analysis. Thousand Oaks, CA : Sage Publications.

Habibi, N. (2009). The impact of the global economic crisis on Arab countries: A year-end assessment. Crown Center for Middle East Studies, No. 40. Brandeis University.

Hale, J. E., Dulek, R. E., \& Hale, D. P. (2005). Crisis response communication challenges. Journal of Business Communication, 42(2): 112-134.

Hanif, N. (3 August 2016). A history of airplane crashes in the UAE. The National. Retrieved from

https://www.thenational.ae/uae/transport/a-history-of-airplane-crashes-in-the-uae-1.137401

Hilden, S., \& Tikkamaki, K. (2013). Reflective Practice as a Fuel for Organizational Learning. Administrative Sciences, 3, 76-95. http://dx.doi.org/10.3390/admsci3030076

Hough, M. G., \& Spillan, J. E. (2005). Crisis Planning: Increasing Effectiveness, Decreasing Discomfort. Journal of Business \& Economics Research, 3(4), 19-24.

Idris, S., \& Dharmasiri, L. M. (2015). Flood risk inevitability and flood risk management in urban areas: A review. Journal of Geography and Regional Planning, 8(8), 205-209. https://doi.org/10.5897/JGRP2015.0510

Johnson, T. P. (2005). Snowball Sampling. Encyclopedia of Biostatistics. https://doi.org/10.1002/0470011815.b2a16070

Jung, Y., Jeong, M. G., \& Mills, T. (2014). Identifying the Preferred Leadership Style for Managerial Position of Construction Management. International Journal of Construction Engineering and Management, 3(2), 47-56. http://dx.doi.org/10.5923/j.ijcem.20140302.02

Kantamara, P., \& Ractham, V. V. (2014). Single-loop vs. double-loop learning: an obstacle or a success factor for organizational learning. International Journal of Education and Research, 2(7), 55-62.

Ki, E., \& Brown, K. (2013). The Effects of Crisis Response Strategies on Relationship Quality Outcomes. Journal of Business Communication, 50(4), 403-420. Retrieved from Business Source Complete, Ipswich, MA.

Lalonde, C. (2007). Crisis Management and Organizational Development: Towards the Conception of a Learning Model in Crisis Management. Organization Development Journal, 25(1), 17.

Lawrence, J., \& Tar, U. (2013). The use of Grounded Theory Technique as a Practical Tool for Qualitative Data Collection and Analysis. The Electronic Journal of Business Research Methods, 11(1), 29-40. 
Leung, L. (2015). Validity, reliability, and generalizability in qualitative research. Journal of

Family Medicine and Primary Care, 4(3), 324-327. https://doi.org/10.4103/2249-4863.161306

Liggett - Nichols, K. (2013). The Impact and Implementation of Learning Intervention on Management and Organizational Practice in a Non-Profit Setting (Doctoral dissertation, Robinson College of Business of Georgia State University). http://scholarworks.gsu.edu/bus_admin_diss/30

Maitlis, S., \& Christianson, M. (2014). Sensemaking in Organizations: Taking Stock and Moving Forward. The Academy of Management Annals, 8(1): 57-125.

Mansfeld, Y., \& Winckler, O. (2015). Can this be spring? Assessing the impact of the "Arab Spring" on the Arab tourism industry. Tourism Review, 63(2), 205-223. UDC: 338.482:316(53)

Manuela Jr., W. S, (2011). Factors Affecting Airline Profits: Evidence from the Philippines. The Journal of Applied Business Research, 27(6), 17-22.

Marling, C. D. (2012). Social Construction of Learning. In Encyclopedia of the Sciences of Learning (Vol. 2, $\quad$ pp. $\quad$ 3095-3098). US: https://doi.org/10.1007/978-1-4419-1428-6_96

Martensson, M. (2000). A critical review of knowledge management as a management tool. Journal of Knowledge Management, 4(3), 204-216.

Martins, E. C., \& Terblanche, F. (2003). Building organizational culture that stimulates creativity and innovation. European Journal of Innovation Management, 6(1), 64-74. https://doi.org/10.1108/14601060310456337

McDonald, L. M., Sparks, B., \& Glendon, A. I. (2010). Stakeholder reactions to company crisis communication and causes. Public Relations Review, 36(3), 263-271.

Mohn, T. (2015). Cancelled Flights From Snowstorm Cost U.S. Economy \$230 Million In Lost Passenger Spending. Retrieved from www.forbes.com.

Omotayo, F. O. (2015). Knowledge Management as an important tool in Organizational Management: A Review of Literature. Library Philosophy and Practice (e-journal). Paper 1238. http://digitalcommons.unl.edu/libphilprac/1238

Pangarkar, N. (2016). A framework for effective crisis response. Journal of Organizational Change Management, 29(4), 464 - 483. https://doi.org/10.1108/JOCM-04-2015-0063

Palmer, B. (2012, June 14). Shakes On a Plane: Can turbulence cause a plane crash? Retrieved from http://www.slate.com/articles/news_and_politics/explainer/2012/06/can_turbulence_cause_a_ plane_crash_html

Paraskevas, A., Altinay, L., McLean, J., \& Cooper, C. (2013). Crisis knowledge in tourism: Types, flows and governance. Annals of Tourism Research, 41, 130-152. 
doi:10.1016/j.annals.2012.12.005

Patten, M. L. (2016). Understanding Research Methods: An Overview of the Essentials, 9th Edition. New York: Routledge, Taylor \& Francis Group.

Paulin, D., \& Sunneson, K. (2012). Knowledge Transfer, Knowledge Sharing and Knowledge Barriers - Three Blurry Terms in KM. The Electronic Journal of Knowledge Management, 10 (1), pp. 81-91

Petzall, B. J., Parker, P. E., \& Stoeberl, P. (2000). Another side to downsizing: survivors' behavior and self-affirmation. Journal of Business and Psychology, 14(4), 593-603. https://doi.org/10.1023/A:1022990214073

Pierre, M. S., Hofinger, G., Buerschaper, C., \& Simon, R. (2011). Crisis management in acute care settings: Human factors, team psychology, and patient safety in a high stakes environment. Berlin: Springer.

Rains, B. (2014). The Path to Operational Excellence Through Operational Discipline: An Ongoing Journey of Improvement. Retrieved from http://www.dupont.com

Rehman, W., \& Naeem, H. (2012). The impact of downsizing on the performance of survived employees: A case study of Pakistan. African Journal of Business Management, 6(7), 2429-2434. https://doi.org/10.5897/AJBM10.198

Richardson, J. (2014). Double Loop Learning: A Powerful Force for Organizational Excellence. In: proceedings of Pacific Northwest Software Quality Conference (PNSQC 2014), Portland, Oregon, United States.

Robinson, O. C. (2014). Sampling in Interview-Based Qualitative Research: A Theoretical and Practical Guide. Qualitative Research in Psychology, 11(1), 25-41. http://dx.doi.org/10.1080/14780887.2013.801543

Sandler, T. (2014). The analytical study of terrorism: Taking stock. Journal of Peace Research, 51(2), 257-271. https://doi.org/10.1177/0022343313491277

Schiliro, D. (2013). Diversification and Development of the UAE's economy. MPRA Paper No. 47089. University of Messina. Online at https://mpra.ub.uni-muenchen.de/47089/

Siomkos, G. J. (2000). Managing airline disasters: the role of consumer safety perceptions and sense-making. Journal of air transport management, 6: 101-108.

Simmons, C. (2009). Crisis Management \& Organizational Learning: How Organizations Learn from Natural Disasters. Available at SSRN: https://ssrn.com/abstract=1351069 or http://dx.doi.org/10.2139/ssrn.1351069

Sohn, Y. J., \& Lariscy, R. W. (2014). Understanding Reputational Crisis: Definition, Properties, and Consequences. Journal of Public Relations Research, 26(1), 23-43.

Steele, J. (2015, February 18). How Safe Is Air Travel? The Statistical Truth. Retrieved April 27, 2017, from https://thepointsguy.com/2015/02/how-safe-is-air-travel-the-statistical-truth/ 
Stephens, K. K., Malone, P. C., \& Bailey, C. M. (2005). Communicating with stakeholders during a crisis. Journal of Business Communication, 42(4), 390-419.

Stinglhamber, F., Marique, G., Caesens, G., Desmette, D., Hansez, I., \& Hanin D. (2015). Employees' Organizational Identification and Affective Organizational Commitment: An $\begin{array}{lllll}\text { Integrative } \quad \text { Approach. } & \text { PLoS } & \text { ONE, } & \text { 10123), }\end{array}$ https://doi.org/10.1371/journal.pone.0123955

Taneja, S., Pryor, M., Sewell, S., \& Recuero, A. (2014). Strategic Crisis Management: A Basis for Renewal and Crisis Prevention. Journal Of Management Policy \& Practice, 15(1), 78-85. Retrieved from Business Source Complete, Ipswich, MA

Thomas, D. R. (2017). Feedback from research participants: Are member checks useful in qualitative research? Qualitative Research in Psychology, 14(1), 23-41. http://dx.doi.org/10.1080/14780887.2016.1219435

Topping, P. (2002). Managerial Leadership. New York: McGraw-Hill.

Varnai, S. (2005). Crisis Communication as Effective Tool of Change Management. In: proceedings of 3rd International Conference on Management, Enterprise and Benchmarking (MEB 2005), Obuda University, Budapest, Hungary.

Van Dick, R., Drzensky, F., \& Heinz, M. (2016). Goodbye or Identify: Detrimental Effects of Downsizing on Identification and Survivor Performance. Frontiers in Psychology, 7, 771. https://doi.org/10.3389/fpsyg.2016.00771

Vasenska, I. (2013). Organizational learning and employee empowering increasing tourist destination performance. In: Proceedings of the 2013 Active Citizenship by Knowledge Management \& Innovation: Proceedings of the Management, Knowledge and Learning International Conference, Zadar, Croatia, 19-21 June 2013.

Wachter, J. K. \& Yorio, P. L. A system of safety management practices and worker engagement for reducing and preventing accidents: An empirical and theoretical investigation. Accident Analysis \& Prevention, 68, 117-130. http://doi.org/10.1016/j.aap.2013.07.029

Wang, J., Qiu, R., Wang, Y., \& Wu, J. (2014). Empirical Study and Discriminant Analysis of Airline Services in the Yangtze River Delta of China. American Journal of Tourism Research, 3(1), 1-8. https://doi.org/10.11634/216837861403498

Wirtz, J., Heracleous, L., \& Pangarkar, N. (2008). Managing human resources for service excellence and cost effectiveness at Singapore Airlines. Managing Service Quality: An International Journal, 18(1), 4-19. https://doi.org/10.1108/09604520810842812

Zhang, R., Hu, W., Xinghua, D., \& Chen, J. Q. (2015). IS Management and IS Engineering in the Era of Big Data. In: proceedings of the 5th International Conference on IS Management and Evaluation (ICIME 2015), Xi'an University of Technology, Shaanxi, China, 28-29 May 2015. 


\section{Macrothink}

International Journal of Learning and Development

ISSN 2164-4063

\section{Copyright Disclaimer}

Copyright for this article is retained by the author(s), with first publication rights granted to the journal.

This is an open-access article distributed under the terms and conditions of the Creative Commons Attribution license (http://creativecommons.org/licenses/by/4.0/). 